\title{
Comparison of measured ethanol and calculated ethanol using osmolal gap and osmolarity formulas
}

\author{
Elif Guney Boru', Turan Turhan², Dogan Yucel $^{3}$ \\ 'Department of Clinical Biochemistry, Oltu State Hospital, Erzurum, Turkey \\ 2Department of Clinical Biochemistry, Ankara Numune Training And Research Hospital, Ankara, Turkey \\ ${ }^{3}$ Department of Clinical Biochemistry, Ankara Training And Research Hospital, Ankara, Turkey
}

\begin{abstract}
Objectives: Osmolality can be measured with an osmometer, and it can also be calculated using formulas that include the level of some osmotically active serum components. The difference between measured and calculated osmolality is referred to as the osmolal gap. The osmolal gap indirectly indicates the presence of osmotically active substances other than sodium, urea, and glucose. The aim of this study was to calculate the osmolal gap using 6 osmolarity formulas published in the literature and compare the measured ethanol concentrations with various ethanol calculation formulas that include the osmolal gap.

Methods: Serum ethanol, glucose, potassium, sodium, and urea levels were measured. Serum osmolarity was calculated with 6 formulas and converted to osmolality ( $\mathrm{mOsmol} / \mathrm{L}-\mathrm{mOsmol} / \mathrm{kg} \mathrm{H}_{2} \mathrm{O}$ ) using a converting factor. The osmolal gap was determined using measured and calculated osmolality with 6 different formulas for each sample. The osmolal gap values were multiplied by the ethanol coefficient used to ascertain the effect of ethanol on serum osmolality in order to obtain the amount of ethanol in the samples.

Results: A positive correlation was observed between the 24 calculated ethanol levels and measured ethanol levels. No statistically significant difference was seen between the measured ethanol levels and 1 of the formulas, but there were systematic differences between them.

Conclusion: Estimating the ethanol concentration with this type of approach is particularly inappropriate in forensic cases. The osmolal gap should only be used for screening toxic alcohols as an adjunct to clinical decision-making in emergency departments when ethanol cannot be measured, as in a case of alcohol intoxication.
\end{abstract}

Keywords: Ethanol, Osmolal gap, Osmolarity formula

$\mathrm{O}$ smolality is the concentration of the osmoles of solute dissolved per kilogram of pure water $\left(\mathrm{mOsmol} / \mathrm{kg} \mathrm{H}_{2} \mathrm{O}\right)$, whereas osmolarity is the concentration of the osmoles of solute dissolved per liter of solution ( $\mathrm{mOsmol} / \mathrm{L}$ ). These 2 terms can be used interchangeably, but osmolality is a more accurate term thermodynamically. Solution concentrations are expressed on the basis of weight, and therefore, it is independent of temperature and pressure. In contrast, solution concentrations are expressed on the basis of volume in osmolarity, and changes in volume can occur depending on the thermal expansion of the solution. As a result, osmolarity can lead to incorrect results in cases of hyperlipidemia or hyperproteinemia, or in the presence of osmotically active substances, such as alcohol or mannitol [1-3].

The osmolal gap is the difference between measured osmolality and calculated osmolality. Normally, the osmolal gap is less than $10 \mathrm{mOsmol} / \mathrm{kg} \mathrm{H}_{2} \mathrm{O}$ [4].

A high concentration of alcohol, such as ethanol, methanol, isopropanol, ethylene glycol, or propylene glycol causes hyperosmolality and a high osmolal gap in proportion with the 
Table 1. Osmolarity formulas used in the study

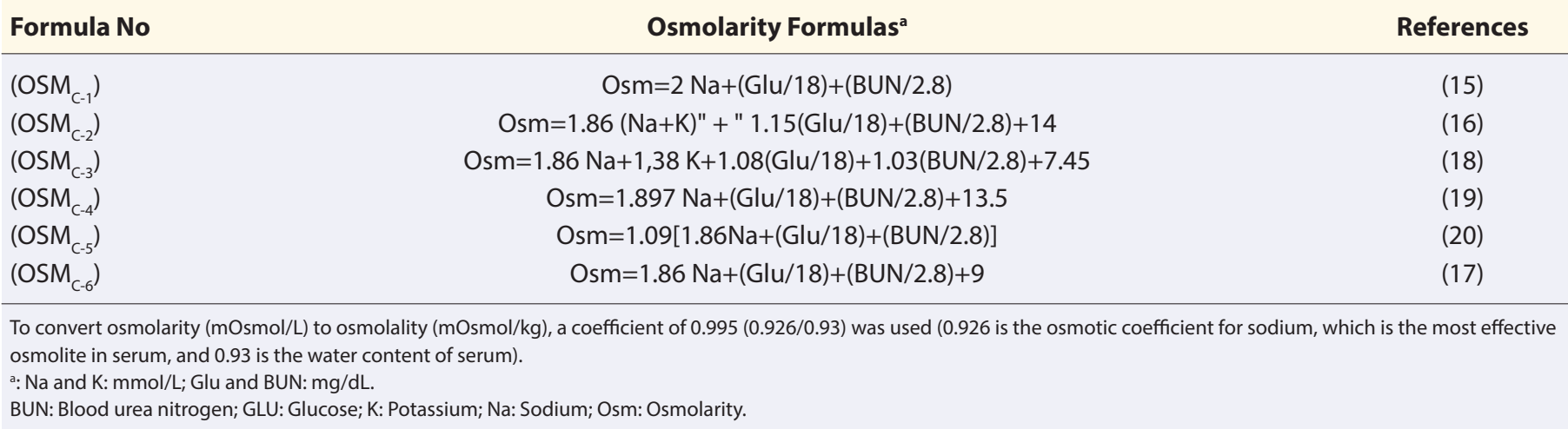

severity of exposure. Several studies have been performed calculating serum ethanol concentrations using various formulas and the osmolal gap as a practical approach when it would take time for the measurement of toxic alcohol or when these substances cannot be measured $[5,6]$.

Nowadays, ethanol is an easily obtainable substance, and therefore, in this study, the aim was to calculate the osmolal gap using 6 osmolarity formulas published in the literature and compare the measured ethanol concentrations with estimated ethanol concentrations obtained from various ethanol calculation formulas that include the osmolal gap.

\section{Materials and Methods}

This research was designed as a prospective study. The study included 257 individuals (44 females, 213 males) who were admitted to the Ankara Numune Training and Research Hospital emergency department with a serum ethanol concentration between 2.60 and $80.31 \mathrm{mmol} / \mathrm{L}(12 \mathrm{mg} / \mathrm{dL}$ and $370 \mathrm{mg} / \mathrm{dL}$ ). Lipemic, hemolyzed samples and diabetic, hypernatremic, hyperproteinemic, or mannitol-treated patients were excluded.

Between-day imprecisions (coefficient of variation [CV] \%), mean, and standard deviation (SD) of ethanol, sodium, potassium, glucose, and urea parameters were determined using internal quality control materials. These parameters were measured using a Beckman Coulter AU680 autoanalyser (Beckman Coulter, Inc., Brea, CA, USA) and 6 different osmolarity formulas were used to calculate osmolarity values (Table 1). In the vast majority of publications, these formulas are used to calculate serum osmolality, but in fact, these are formulas of serum osmolarity, because the unit used is $\mathrm{mOsmol} / \mathrm{L}$. For that reason, in this study, a correction coefficient of 0.995 was used to convert osmolarity to osmolality $[7,8]$.

There was no available quality control material for the osmometer, so we used 2 levels of serum pool created from patients' and normal individuals' sera. During the study period, between-day variations were evaluated using the samples obtained from the serum pool and mean, SD, and CV\% values were calculated. For calibration, deionized water $(0 \mathrm{mOsmol} /$ $\mathrm{kg} \mathrm{H}_{2} \mathrm{O}$ ) and a calibration solution (400 mOsmol/kg $\mathrm{H}_{2} \mathrm{O}$ ) supplied by the manufacturer were used.

Serum osmolality was measured with the osmometer (Knauer Wissenschaftliche Geräte $\mathrm{GmbH}$, Berlin, Germany) using the freezing-point depression method. For each sample, 6 different osmolal gap values were determined using calculated and measured osmolality values. These osmolal gap values were used in the 4 formulas provided in Table 2 , and the results were

Table 2. Formulas used to estimate ethanol concentration

\begin{tabular}{lc}
\hline Formulas & References \\
\hline Ethanol $(\mathrm{mg} / \mathrm{dL})=\mathrm{OG} \times 3.7$ & $(10)$ \\
Ethanol $(\mathrm{mg} / \mathrm{dL})=\mathrm{OG} \times 4.0$ & $(9)$ \\
Ethanol $(\mathrm{mg} / \mathrm{dL})=\mathrm{OG} \times 4.2$ & $(11)$ \\
Ethanol $(\mathrm{mg} / \mathrm{dL})=\mathrm{OG} \times 4.6$ & $(5)$
\end{tabular}

OG: Osmolal gap.

Table 3. Descriptive statistics for the concentration of selected substances in serum

\begin{tabular}{lccc}
\hline & $\begin{array}{c}\text { Mean } \\
\mathbf{m m o l} / \mathbf{L}(\mathbf{m g} / \mathbf{d L})\end{array}$ & $\begin{array}{c}\mathbf{\pm S D} \\
\mathbf{m m o l} / \mathbf{L}(\mathbf{m g} / \mathbf{d L})\end{array}$ & $\begin{array}{c}\text { Range } \\
\mathbf{m m o l} / \mathbf{L}(\mathbf{m g} / \mathbf{d L})\end{array}$ \\
\hline Sodium & 140 & \pm 2.74 & $123-147$ \\
Potasium & 3.95 & \pm 0.44 & $1.51-6.68$ \\
Glucose & $5.77(104)$ & $\pm 1.46( \pm 26.40)$ & $2.50-16.04(45-289)$ \\
BUN & $0.45(11.92)$ & $\pm 0.14( \pm 3.83)$ & $0.11-1.34(2.80-35.19)$ \\
Ethanol & $34.38(158.37)$ & $\pm 17.52( \pm 80.72)$ & $2.60-80.31(12-370)$ \\
\hline
\end{tabular}

BUN: Blood urea nitrogen. 

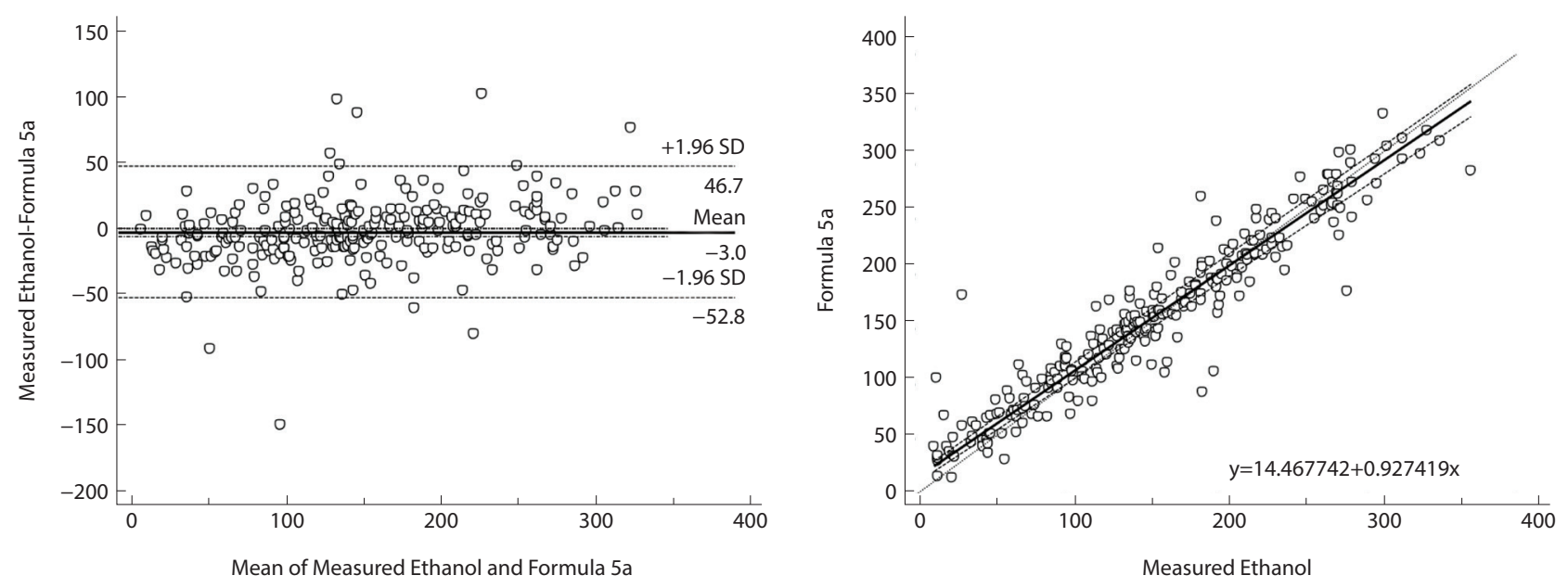

Figure 1. (a) Bland-Altman plots for Formula 5a. The averages of the measured ethanol and the calculated ethanol are shown on the x-axis, and the differences between the measured ethanol and the calculated ethanol on the $y$-axis; (b) Passing-Bablok regression analysis between measured ethanol concentration and ethanol calculated with Formula 5a with a 95\% confidence interval (results obtained from the formula on the $y$-axis, and results obtained from the measurement on the $x$-axis).

evaluated in estimations of ethanol concentration [5, 9-11].

The ethanol concentrations estimated from formulas were compared with ethanol concentrations measured using the enzymatic method. The usefulness of the osmolal gap coefficient and osmolality formulas was evaluated for estimating the ethanol concentration.

The Kolmogorov-Smirnov test was performed for normality. For normally distributed parameters, a paired sample t-test was used to evaluate the difference between the measured ethanol concentration and the calculated ethanol concentration. Pearson's correlation was used to measure the association between variables. To compare the coherence between ethanol measurements and formulas, Passing-Bablok regression analysis was performed. The Bland-Altman method was used to evaluate the agreement of differences between measured ethanol concentration and calculated ethanol concentration. Statistical significance was defined as $p<0.05$.

\begin{tabular}{|c|c|c|}
\hline & Median (min-max) & $P$ value \\
\hline $\mathrm{OSM}_{\mathrm{M}}(\mathrm{mOsmol} / \mathrm{kg})$ & $333(292-431)$ & \\
\hline $\mathrm{OSM}_{\mathrm{c}-1}(\mathrm{mOsmol} / \mathrm{L})$ & 286 (254-299) & $<0.001$ \\
\hline $\mathrm{OSM}_{\mathrm{C}-2}(\mathrm{mOsmol} / \mathrm{L})$ & $293(262-306)$ & $<0.001$ \\
\hline $\mathrm{OSM}_{\mathrm{C}-3}(\mathrm{mOsmol} / \mathrm{L})$ & $284(253-297)$ & $<0.001$ \\
\hline $\mathrm{OSM}_{\mathrm{C}-4}(\mathrm{mOsmol} / \mathrm{L})$ & $289(259-302)$ & $<0.001$ \\
\hline $\mathrm{OSM}_{\mathrm{C}-5}(\mathrm{mOsmol} / \mathrm{L})$ & $290(258-304)$ & $<0.001$ \\
\hline $\mathrm{OSM}_{\mathrm{C}-6}(\mathrm{mOsmol} / \mathrm{L})$ & 279 (249-292) & $<0.001$ \\
\hline
\end{tabular}

$\mathrm{OSM}_{\mathrm{c}}$ : Calculated osmolality; OSMM: Measured osmolality.

\section{Results}

The mean age of the individuals was 32.6 years (range: 18-74 years). The mean age of the male patients was 33.2 years (range: 18-74 years) and the mean female patient age was 29.8 years (range: 19-53 years). Concentrations of glucose, sodium, potassium, BUN and ethanol in individuals' serum shown in Table 3.

For glucose, sodium, potassium, urea, and ethanol, the between-day imprecisions were $1.58 \%-1.20 \%, 1.01 \%-1.08 \%$, $0.98 \%-1.11 \%, 1.6 \%-1.6 \%$, and $2.71 \%-2.33 \%$ respectively (from internal quality control program level 1 and 2), and for osmolality, $0.88 \%-0.80 \%$ (from serum pool, normal and high level).

When osmolality was calculated, a statistically significant difference was observed between the calculated osmolality and the measured osmolality $(p<0.001)$ (Table 4$)$.

The mean of the measured ethanol concentration was $34.38 \pm 17.52 \mathrm{mmol} / \mathrm{L}(158.37 \pm 80.72 \mathrm{mg} / \mathrm{dL})$. A strong positive correlation was observed between the measured and the calculated ethanol concentrations (Table 5).

Formula 5 a demonstrated a smaller mean difference of -0.65 $\mathrm{mmol} / \mathrm{L}(-3.0 \mathrm{mg} / \mathrm{dL})$, and a $95 \%$ limit of agreement, ranging from -52.8 to 46.7 , and there was no significant difference between the mean of Formula $5 \mathrm{a}$ and measured ethanol $(p=0.057)$ (Fig. 1a). But when Passing-Bablok regression analyses were performed, constant and proportional differences between the measurement and the Formula 5a result were observed (Fig. 1b).

\section{Discussion}

Gas chromatography is the reference method for ethanol measurement, but it is not available in typical laboratories. This 


\begin{tabular}{|c|c|c|c|}
\hline $1 \mathrm{a}$ & OG1X3.7 & $38.79 \pm 16.20(178.72 \pm 74.62)$ & 0.950 \\
\hline $1 b$ & OG $1 \times 4.0$ & $41.93 \pm 17.57(193.19 \pm 80.70)$ & 0.950 \\
\hline 1c & OG1X4.25 & $44.55 \pm 18.61(205.25 \pm 85.77)$ & 0.950 \\
\hline $2 a$ & OG2X3.7 & $33.18 \pm 16.18(152.87 \pm 74.53)$ & 0.951 \\
\hline $2 b$ & OG2X4.0 & $35.87 \pm 17.49(165.27 \pm 80.58)$ & 0.951 \\
\hline $2 c$ & OG2X4.25 & $38.11 \pm 18.58(175.61 \pm 85.62)$ & 0.951 \\
\hline $2 d$ & OG2X4.6 & $41.25 \pm 21.21(190.07 \pm 92.70)$ & 0.951 \\
\hline $3 a$ & OG3X3.7 & $40.29 \pm 16.20(185.61 \pm 74.64)$ & 0.951 \\
\hline $4 b$ & OG4X4.0 & $38.95 \pm 17.52(179.45 \pm 80.74)$ & 0.951 \\
\hline $4 c$ & OG $4 X 4.25$ & $41.38 \pm 18.63(190.63 \pm 85.84)$ & 0.951 \\
\hline $4 d$ & OG4X4.6 & $44.79 \pm 20.17(206.35 \pm 92.93)$ & 0.951 \\
\hline $5 a$ & OG5X3.7 & $35.03 \pm 16.20(161.39 \pm 74.62)$ & 0.950 \\
\hline $5 b$ & OG5X4.0 & $37.89 \pm 17.51(174.54 \pm 80.67)$ & 0.949 \\
\hline $5 c$ & OG5X4.25 & $40.25 \pm 18.60(185.44 \pm 85.72)$ & 0.950 \\
\hline $5 d$ & OG5X4.6 & $43.56 \pm 20.14(200.68 \pm 92.79)$ & 0.950 \\
\hline $6 a$ & OG6X3.7 & $43.80 \pm 16.24(201.79 \pm 74.81)$ & 0.951 \\
\hline $6 b$ & OG6X4.0 & $47.35 \pm 17.55(218.15 \pm 80.88)$ & 0.951 \\
\hline $6 c$ & OG6X4.25 & $49.72 \pm 18.43(229.08 \pm 84.91)$ & 0.951 \\
\hline
\end{tabular}

OG: Osmolal gap.

method requires expensive equipment and educated technical staff; therefore, ethanol is generally measured with the enzymatic method. In some laboratories, the enzymatic method is not possible, and so the calculated osmolal gap provides a practical approach, but it must be remembered that there are several conditions that can increase the osmolal gap other than ethanol, such as diabetes mellitus, dehydration, or hypernatremia [12-14].

In the literature, many formulas have been defined for osmolality calculation and ethanol estimation; however, there is still no consensus on which formula is most accurate [15-20].

The coefficient of $1 / 4.6$ is used to calculate the contribution of ethanol to serum osmolarity, caused by ethanol's molecular mass. Ethanol is a nonideal liquid, like serum; therefore, the phrase " $1 \mathrm{mmol} / \mathrm{L}$ of the compound would produce $1 \mathrm{mOs}$ $\mathrm{m} / \mathrm{L}$ of osmolarity" would be invalid for ethanol and makes the aforementioned coefficient of ethanol open to debate.

In this study, we evaluated osmolality formulas and ethanol estimation formulas, and a statistically significant difference between measured osmolality and calculated osmolality was observed $(p<0.001)$. This result revealed the presence of osmotically active substances that were not included in osmo- lality formulas. A strongly positive correlation was found between 24 ethanol estimation formulas and enzymatic ethanol measurements (Table 5). When examining the mean difference, there was no significant difference between Formula $5 a$ and measured ethanol, but there were constant and proportional differences between the measurement and the Formula 5 a result.

Our results indicating that the coefficient for ethanol should be greater than 1/4.6 agreed with the findings of several studies [9-11]. But it may vary with increasing ethanol concentrations, as ethanol may affect the solubility of solutes in serum as a solvent. Although Formula 5 a would achieve the closest value to measured ethanol concentration, using ethanol formulas instead of ethanol measurement is inappropriate due to of systematic (constant and proportional) differences between measurement and calculation.

The osmolal gap may be close to zero in healthy individuals but the presence of ethanol or another osmotically active substance (methanol, ethylene glycol, etc.) or their metabolites may change the solubility of other ingredients in the serum. As a result, with the calculated ethanol value, a higher or lower ethanol concentration than expected may be observed. Fur- 
thermore, the absence of consensus on molal-molar conversion can be another reason for differences between results.

\section{Conclusion}

Due to the presence of various osmolarity formulas in the literature and contradictions between osmolality and osmolarity usage, the use of the osmolal gap is limited. For this reason, estimating ethanol concentrations with this type of approach is particularly inappropriate in forensic cases. Considering these variable factors and the nonideal nature of ethanol, the osmolal gap should only be used for screening toxic alcohols as an adjunct to clinical decision-making in emergency departments, such as in a case of alcohol intoxication, since it is the metabolites of alcohol that cause alcohol toxicity rather than the alcohol itself, and it takes time for toxicity symptoms to appear. When ethanol is measured, it can be used with the osmolal gap to evaluate the residual osmolal gap to reveal other toxic substances.

Conflict of interest: None declared.

Peer-review: Externally peer-reviewed.

Authorship contributions: Concept - E.G.B., T.T., D.Y.; Design E.G.B., T.T., D.Y.; Supervision - E.G.B., T.T., D.Y.; Fundings - T.T., D.Y.; Materials - E.G.B.; Data collection \&/or processing - E.G.B.; Analysis and/or interpretation - E.G.B.; Literature search - E.G.B.; Writing - E.G.B.; Critical review - T.T., D.Y.

\section{References}

1. Lord RC. Osmosis, osmometry, and osmoregulation. Postgrad Med J 1999;75:67-73. [CrossRef]

2. Koga Y, Purssell RA, Lynd LD. The irrationality of the present use of the osmole gap: applicable physical chemistry principles and recommendations to improve the validity of current practices. Toxicol Rev 2004;23:203-11. [CrossRef]

3. Polancic JE. Electrolytes. In: Bishop ML, Fody EP, Schoeff LE, editors. Clinical Chemistry: Principles, Techniques, and Correlations. 6th ed. Lippincott Williams \& Wilkins; 2010. p. 357.

4. Kapur G, Valentini RP, Imam AA, Jain A, Mattoo TK. Serum osmolal gap in patients with idiopathic nephrotic syndrome and severe edema. Pediatrics 2007;119:e1404-7. [CrossRef]

5. Olson KR. Comprehensive Evaluation and Treatment. In: Olson $\mathrm{KR}$, Anderson IB, Clark RF, editors. Poisoning \& drug overdose. 4th ed. Lange Medical Books/McGraw-Hill; 2004. p. 33.

6. Weisberg HF. Osmolality-calculated, "delta," and more formulas. Clin Chem 1975;21:1182-5.

7. Fazekas AS, Funk GC, Klobassa DS, Rüther H, Ziegler I, Zander $\mathrm{R}$, et al. Evaluation of 36 formulas for calculating plasma osmoIality. Intensive Care Med 2013;39:302-8. [CrossRef]

8. D'Orazio P MM. Electrochemistry and Chemical Sensors. In: Burtis CA, Ashwood ER, Bruns DE, editors. 4th ed. Elsevier Saunders; 2006. p. 101.

9. Garrard A, Sollee DR, Butterfield RC, Johannsen L, Wood A, Bertholf RL. Validation of a pre-existing formula to calculate the contribution of ethanol to the osmolar gap. Clin Toxicol (Phila) 2012;50:562-6. [CrossRef]

10. Purssell RA, Pudek M, Brubacher J, Abu-Laban RB. Derivation and validation of a formula to calculate the contribution of ethanol to the osmolal gap. Ann Emerg Med 2001;38:653-9.

11. Carstairs SD, Suchard JR, Smith T, Simon LV, Kalynych CJ, Shimada $\mathrm{M}$, et al. Contribution of serum ethanol concentration to the osmol gap: a prospective volunteer study. Clin Toxicol (Phila) 2013;51:398-401. [CrossRef]

12. Tormey WP. Are the increasing clinical demands for osmolality measurements and their associated electrolytes appropriate? Ir J Med Sci 1997;166:75-9. [CrossRef]

13. Krasowski MD, Wilcoxon RM, Miron J. A retrospective analysis of glycol and toxic alcohol ingestion: utility of anion and osmolal gaps. BMC Clin Pathol 2012;12:1. [CrossRef]

14. Shin JM, Sachs G, Kraut JA. Simple diagnostic tests to detect toxic alcohol intoxications. Transl Res 2008;152:194-201.

15. Mahon WA, Holland J, Urowitz MB. Hyperosmolar, non-ketotic diabetic coma. Can Med Assoc J 1968;99:1090-2.

16. Khajuria A, Krahn J. Osmolality revisited-deriving and validating the best formula for calculated osmolality. Clin Biochem 2005;38:514-9. [CrossRef]

17. Dorwart WV, Chalmers L. Comparison of methods for calculating serum osmolality form chemical concentrations, and the prognostic value of such calculations. Clin Chem 1975;21:1904.

18. Bhagat Cl, Garcia-Webb P, Fletcher E, Beilby JP. Calculated vs measured plasma osmolalities revisited. Clin Chem 1984;30:1703-5.

19. Rasouli M, Kalantari KR. Comparison of methods for calculating serum osmolality: multivariate linear regression analysis. Clin Chem Lab Med 2005;43:635-40. [CrossRef]

20. Bianchi V, Bidone P, Arfini C. Serum and urine: osmolality calculated or measured osmolality? RIMeL/IJLaM 2009;5:206-11. 